\title{
Initial Assessment of BDS PPP-B2b Service: Precision of Orbit and Clock Corrections, and PPP Performance
}

\author{
Zhixi Nie $^{1}\left(\mathbb{D}\right.$, Xiaofei Xu $^{1, *(\mathbb{D})}$, Zhenjie Wang ${ }^{1}(\mathbb{D})$ and Jun Du ${ }^{2}$ \\ 1 College of Oceanography and Space Informatics, China University of Petroleum, Qingdao 266580, China; \\ niezhixi@upc.edu.cn (Z.N.); sdwzj@upc.edu.cn (Z.W.) \\ 2 Qingdao Shihua Crude Oil Terminal, Qingdao Port, Qingdao 266500, China; Duj.sh@qdport.com \\ * Correspondence: b19010058@s.upc.edu.cn
}

Citation: Nie, Z.; Xu, X.; Wang, Z.; $\mathrm{Du}, \mathrm{J}$. Initial Assessment of BDS PPP-B2b Service: Precision of Orbit and Clock Corrections, and PPP Performance. Remote Sens. 2021, 13, 2050. https://doi.org/10.3390/ rs13112050

Academic Editors: José Fernández and Ali Khenchaf

Received: 13 April 2021

Accepted: 19 May 2021

Published: 22 May 2021

Publisher's Note: MDPI stays neutral with regard to jurisdictional claims in published maps and institutional affiliations.

Copyright: $\odot 2021$ by the authors. Licensee MDPI, Basel, Switzerland. This article is an open access article distributed under the terms and conditions of the Creative Commons Attribution (CC BY) license (https:// creativecommons.org/licenses/by/ $4.0 /)$.

\begin{abstract}
On 31 July 2020, the Beidou global navigation satellite system (BDS-3) was officially announced as being commissioned. In addition to offering global positioning, navigation, and timing (PNT) services, BDS-3 also provides precise point positioning (PPP) augmentation services. The satellite orbit correction, clock correction and code bias correction of BDS-3 and other global navigation satellite systems (GNSS) are broadcast by the BDS-3 geostationary earth orbit (GEO) satellites through the PPP-B2b signal. The PPP-B2b service is available for users in China and the surrounding area. In this study, an initial assessment of the PPP-B2b service is presented, with collected 3-day PPP-B2b messages. Based on broadcast ephemeris and PPP-B2b messages, the precise satellite orbits and clock offsets can be recovered. This precision is evaluated with the precise ephemeris from the GeoForschungsZentrum Potsdam (GFZ) analysis center as references. The results indicate that the accuracy of BDS-3 satellite orbits in the direction of radial, along-track, and cross-track is $0.138,0.131$, and $0.145 \mathrm{~m}$, respectively, and for GPS a corresponding accuracy of 0.104 , 0.160 , and $0.134 \mathrm{~m}$, respectively, could be obtained. The precision of clock offsets can reach a level of several centimeters for both GPS and BDS-3. Both the performance of static PPP and kinematic PPP are evaluated using the observations from four international GNSS monitoring assessment service (iGMAS) stations. Regarding static PPP, the average convergence time is $17.7 \mathrm{~min}$ to achieve a horizontal positioning accuracy of better than $0.3 \mathrm{~m}$, and a vertical positioning accuracy of better than $0.6 \mathrm{~m}$. The average positioning accuracy in the direction of east, north, and up-directions are 2.4, 1.6 , and $2.3 \mathrm{~cm}$. As to kinematic PPP, the average RMS values of positioning errors in the direction of east, north, and up are $8.1 \mathrm{~cm}, 3.6 \mathrm{~cm}$, and $8.0 \mathrm{~cm}$ after full convergence.
\end{abstract}

Keywords: GNSS; BDS-3; PPP-B2b; orbit correction; clock correction

\section{Introduction}

The Beidou navigation satellite system (BDS) was independently developed by China to provide positioning, navigation, and timing (PNT) services [1,2]. A three-phase strategy has been adopted in the build-up of BDS, including the Beidou demonstration navigation satellite system (BDS-1), Beidou regional navigation satellite system (BDS-2), and Beidou global navigation satellite system (BDS-3). BDS-1 and BDS-2 have been put into use in 2000 and 2012, respectively [3,4], while the construction of BDS-3 was initiated in November 2017 [5]. By the end of June 2020, the whole constellation of BDS-3 was completed, consisting of 24 medium earth orbit (MEO) satellites, 3 geostationary earth orbit (GEO) satellites, and 3 inclined geosynchronous orbit (IGSO) satellites. On 31 July 2020, the BDS-3 system was officially announced as being commissioned. BDS-3 can offer PNT, short message communication (SMC), and international search and rescue (SAR) services. Besides the above services, BDS-3 also provides a precise point positioning (PPP) service [6,7].

PPP is a crucial high-precision global navigation satellite system (GNSS) positioning technology [8-10]. It can provide decimeter-level or even centimeter-level positioning accuracy with a standalone GNSS receiver, by utilizing precise ephemeris products. In the past 
decades, PPP techniques have been widely used for applications in oceanography [11-13], geoscience [14,15] and meteorology [16-18], and precision agriculture [19], etc. The international GNSS service (IGS) has been offering real-time service (RTS) through the internet since 2013 [20,21]. By adopting RTS products, the users can realize the real-time PPP application. However, this service depends on a standing internet access. In addition to the service offered via internet communication, a satellite broadcasting service has also been released by some commercial companies with a high-cost fee, such as StarFix from Furgo [22], StarFire from NavCom [23], and RTX from Trimble [24]. Additionally, PPP augmentation services based on the basic GNSS constellation have also been developed. The Japanese Quasi-Zenith Satellite System (QZSS) provides a centimeter-level accuracy augmentation service (CLAS) for users in Japan [25,26]. The European Galileo constellation is also designed to provide a high-precision PPP service worldwide, with an enabled positioning accuracy at decimeter-level $[27,28]$.

BDS-3 is designed to provide a PPP augmentation service, which is an important innovation for BDS [29]. The satellite orbit correction, clock correction and code bias correction of BDS-3/GPS/GLONASS/GALILEO are supposed to be broadcast by BDS-3 GEO satellites through the PPP-B2b signal. However, the PPP-B2b service only provides corrections of BDS-3 and GPS satellites at present, and the service is only available for users in and around China. According to the structure of the PPP-B2b message, the size is 486 bits for each message, including 6 bits of message type, 456 bits of message data, and 24 bits of cycle redundancy check (CRC). The duration of each message is $1 \mathrm{~s}$. The message type is defined to distinguish the broadcast correction contents. To match with the correction contents of different message types, the correction data are identified with a group of issue of data (IOD), including the issue of data of space state representation (IOD SSR), issue of data of pseudo-random noise mask (IODP), issue of data of orbit and clock correction (IOD Corr), and issue of the navigation data (IODN). The message types and the corresponding contents are summarized in Table 1 [30].

Table 1. The message types and their correction contents.

\begin{tabular}{cc}
\hline Message Type & Correction Content \\
\hline 1 & Satellite mask \\
2 & Satellite orbit correction and user range accuracy \\
3 & Differential code bias \\
4 & Satellite clock correction \\
5 & User range accuracy index \\
6 & Clock correction and orbit correction-combination 1 \\
7 & Clock correction and orbit correction-combination 2 \\
$8-62$ & Reserved \\
63 & Null \\
\hline
\end{tabular}

In this contribution, we carry out an initial assessment of the BDS PPP-B2b service based on the collected 3-day message data. At first, the availability of PPP-B2b messages is analyzed. Then, the precision of PPP-B2b orbit correction and clock corrections are evaluated with the final precise multi-GNSS ephemeris products obtained from the GeoForschungsZentrum Potsdam (GFZ) analysis center as references. Finally, the PPP positioning performance in both static and kinematic mode is assessed, based on the observations from 4 international GNSS monitoring assessment service (iGMAS) stations [31]. The remaining contribution is organized as follows. In Section 2, the method to recover precise orbits and clock offsets from the PPP-B2b messages is described. In addition, the strategy to evaluate the precision of PPP-B2b orbits/clock offsets, and positioning performance with the recovered PPP-B2b orbits/clock offsets, are also introduced. In Section 3, the precision of the recovered PPP-B2b orbits/clock offsets are assessed, with GFZ precise ephemeris as reference. At the same time, the positioning performance is analyzed both in static and kinematic experiments. Finally, several conclusions are drawn in the last section. 


\section{Methodology}

In this section, firstly, the method to calculate precise orbits and clock offsets by using PPP-B2b corrections is presented. Then, the method to evaluate the precision of PPP-B2b orbits and clock offsets is discussed. Finally, the PPP positioning model, based on the recovered PPP-B2b orbits and clock offsets, is described.

\subsection{Recovery of Precise Orbits and Clock Offsets with PPP-B2b Corrections}

The PPP-B2b orbit correction message contains the orbit correction parameters $\left(\delta \mathrm{O}_{\text {radial }}\right.$, $\left.\delta \mathrm{O}_{\text {along }}, \delta \mathrm{O}_{\text {cross }}\right)$ in the radial, along-track, and cross-track directions [30], while the satellite positions computed with broadcast ephemeris are given in the "Earth-center Earth-fixed" (ECEF) frame. Hence, the orbit corrections should be transformed to the ECEF frame. This transformation can be expressed as:

$$
\left[\begin{array}{l}
\delta O_{x} \\
\delta O_{y} \\
\delta O_{z}
\end{array}\right]=\left[\begin{array}{lll}
\boldsymbol{e}_{\text {radial }} & \boldsymbol{e}_{\text {along }} & \boldsymbol{e}_{\text {cross }}
\end{array}\right] \cdot\left[\begin{array}{c}
\delta O_{\text {radial }} \\
\delta O_{\text {along }} \\
\delta O_{\text {cross }}
\end{array}\right]
$$

where $\left[\begin{array}{lll}\delta O_{x} & \delta O_{y} & \delta O_{z}\end{array}\right]^{T}$ represents the orbit correction vector in the ECEF frame, and:

$$
\left\{\begin{array}{c}
\boldsymbol{e}_{\text {radial }}=\frac{r}{|r|} \\
\boldsymbol{e}_{\text {cross }}=\frac{r \times \dot{r}}{|r \times \dot{r}|} \\
\boldsymbol{e}_{\text {along }}=\boldsymbol{e}_{\text {cross }} \times \boldsymbol{e}_{\text {radial }}
\end{array}\right.
$$

$r$ denotes the satellite position vector and $\dot{r}$ stands for the velocity vector; both are computed with broadcast ephemeris. By applying the satellite orbit correction to broadcast satellite positions, the precise satellite positions can be calculated as follows:

$$
\left[\begin{array}{l}
X \\
Y \\
Z
\end{array}\right]_{p r e c, B 2 b}=\left[\begin{array}{l}
X \\
Y \\
Z
\end{array}\right]_{b r d c}-\left[\begin{array}{c}
\delta O_{x} \\
\delta O_{y} \\
\delta O_{z}
\end{array}\right]
$$

where $\left[\begin{array}{lll}X & Y & Z\end{array}\right]_{\text {prec,B2b }}^{T}$ denotes the precise satellite position vector after applying PPPB2b orbit corrections to the broadcast orbits; and $\left[\begin{array}{llll}X & Y & Z\end{array}\right]_{b r d c}^{T}$ represents the satellite position vector calculated with the broadcast ephemeris. It should be noted that IODN in the PPP-B2b message must match with the corresponding field of broadcast ephemeris in recovering a precise orbit.

The PPP-B2b clock correction message contains the correction parameter relative to the clock offset of broadcast ephemeris. The corrected precise satellite clock offset is given by:

$$
d t_{\text {prec, } B 2 b}^{s a t}=d t_{b r d c}^{s a t}-\frac{C_{0}}{c}
$$

where $d t_{b r d c}^{s a t}$ is the satellite clock offset derived from the broadcast ephemeris; $d t_{\text {prec, } B 2 b}^{\text {sat }}$ denotes the precise PPP-B2b clock offset; $C_{0}$ is the PPP-B2b clock correction parameter; and $c$ is the velocity of light.

\subsection{Assessment of the Recovered PPP-B2b Orbits and Clock Offsets}

The precise orbits recovered with PPP-B2b messages are referred to the antenna phase center (APC), while the IGS precise products give the center-of-mass (CoM) of satellites [32]. Therefore, the satellite APC positions need to be converted to the satellite CoM positions 
by applying phase center offset (PCO) corrections [33]. Now the orbit differences can be computed as:

$$
\left[\begin{array}{c}
\Delta X \\
\Delta Y \\
\Delta Z
\end{array}\right]=\left(\left[\begin{array}{l}
X \\
Y \\
Z
\end{array}\right]_{\text {prec }, B 2 b}+A \cdot d \boldsymbol{r}_{P C O}\right)-\left[\begin{array}{l}
X \\
Y \\
Z
\end{array}\right]_{\text {prec, }, G F Z}
$$

where $\left[\begin{array}{ccc}\Delta X & \Delta Y & \Delta Z\end{array}\right]^{T}$ stands for the orbit error vector in ECEF Cartesian coordinates; $A$ denotes the satellite attitude matrix; and $d \boldsymbol{r}_{P C O}$ represents the PCO correction vector for the satellite. $\left[\begin{array}{lll}X & Y & Z\end{array}\right]_{\text {prec,GFZ }}^{T}$ denotes the precise position vector, calculated with GFZ final products.

The calculated orbit errors can be transformed from ECEF Cartesian coordinates to the satellite radial, along-track and cross-track directions:

$$
\left[\begin{array}{c}
\Delta O_{\text {radial }} \\
\Delta O_{\text {along }} \\
\Delta O_{\text {cross }}
\end{array}\right]=\left[\begin{array}{lll}
\boldsymbol{e}_{\text {radial }} & \boldsymbol{e}_{\text {along }} & \boldsymbol{e}_{\text {cross }}
\end{array}\right] \cdot\left[\begin{array}{c}
\Delta X \\
\Delta Y \\
\Delta Z
\end{array}\right]
$$

where $\left[\begin{array}{ccc}\Delta O_{\text {radial }} & \Delta O_{\text {along }} & \Delta O_{\text {cross }}\end{array}\right]^{T}$ is the orbit error vector in the satellite orbital frame. The BDS-3 PPP-B2b service adopts the Beidou coordinate system (BDCS) as a reference frame [34], while the precise products from IGS are referred to the IGS14 frame [35]. In order to eliminate the difference between these two reference frames mentioned above, a Helmert transformation should be applied.

In contrast to orbits, two different types of clock offset products cannot be compared directly. This is due to differences in hardware delays and GNSS-specific timescales. The hardware delay is caused by different tracking modes. To realize the synchronous processing at different tracking modes, a corresponding differential code bias (DCB) correction needs to be applied. The correction algorithm formula is shown below [30]:

$$
\widetilde{l}_{\text {sig }}=l_{\text {sig }}-D C B_{\text {sig }}
$$

where $\widetilde{l}_{\text {sig }}$ is the value of sig signal; $l_{\text {sig }}$ represents the observed clock offset; and $D C B_{\text {sig }}$ denotes the related DCB value.

After the application of DCBs, the differences between the GNSS-specific time-scales must also be eliminated [36]. Typically, a double-difference method is used to remove this bias [37]. In the double-difference method, a reference satellite clock is chosen from the recovered PPP-B2b precise clock offsets, and the single-difference between the reference clock and other satellite clocks can be formed. The same single-differences can also be obtained by using IGS precise clock offsets. Then, the corresponding double-difference values can be formed with the same single-difference pair. The double-difference clock offset can be expressed as:

$$
\nabla \Delta d t_{B 2 b, G F Z}^{\text {sat }}=d t_{\text {prec,B2b}}^{s a t}-d t_{\text {prec,B2b }}^{\text {refsat }}-\left(d t_{\text {prec,GFZ }}^{\text {sat }}-d t_{\text {prec }, G F Z}^{\text {refsat }}\right)
$$

where $\nabla \Delta$ is a double-difference (DD) operator.

\subsection{PPP Positioning with the Recovered PPP-B2b Orbits and Clocks}

The GNSS code and phase observations at the $i$ th frequency read as [38,39]:

$$
\left\{\begin{array}{c}
P_{i}=\rho+c \cdot \delta t_{r}-c \cdot \delta t^{s}+T+\frac{f_{1}^{2}}{f_{i}^{2}} \cdot I_{1}+B_{r, i}-B_{i}^{s}+\varepsilon_{P_{i}} \\
L_{i}=\rho+c \cdot \delta t_{r}-c \cdot \delta t^{s}+T-\frac{f_{1}^{2}}{f_{i}^{2}} \cdot I_{1}+\lambda_{i}\left(N_{i}+b_{r, i}-b_{i}^{s}\right)+\varepsilon_{L_{i}}
\end{array}\right.
$$


where $P_{i}$ and $L_{i}$ are raw code/phase observation; $\rho$ represents the receiver-to-satellite geometry distance; $c$ stands for the speed of light; $\delta t_{r}$ and $\delta t^{s}$ are clock offsets at the receiver and the satellite, respectively; $T$ stands for the tropospheric delay; $f_{i}$ is the frequency value; $I_{1}$ denotes the ionospheric delay for $L_{1} ; \lambda_{i}$ is the wavelength and $N_{i}$ is the integer ambiguity; $B_{r, i}$ and $b_{r, i}$ represent code/phase bias at the receiver; $B_{i}^{s}$ and $b_{i}^{s}$ denote code/phase bias at the satellite; and $\varepsilon_{P_{i}}$ and $\varepsilon_{L_{i}}$ are code/phase unmodelled errors, including thermal noise and multipath. It is noted that existing models should be applied to correct the relativistic effect, Sagnac effect, Shapiro time delay [40], phase windup effect [41] and site displacements [42].

Usually, the ionospheric-free combination is adopted by PPP to eliminate the firstorder ionospheric delay. The dual-frequency code/phase ionospheric-free combinations can be expressed as:

$$
\left\{\begin{array}{c}
P_{I F}=\alpha P_{1}+(1-\alpha) P_{2}=\rho+c \cdot \delta t_{r}-c \cdot \delta t^{s}+T+\varepsilon_{P_{I F}} \\
L_{I F}=\alpha L_{1}+(1-\alpha) L_{2}=\rho+c \cdot \delta t_{r}-c \cdot \delta t^{s}+T+\lambda_{I F} \cdot N_{I F}+\varepsilon_{L_{I F}}
\end{array}\right.
$$

where $\alpha=f_{1}^{2} /\left(f_{1}^{2}-f_{2}^{2}\right) ; \lambda_{I F} N_{I F}=\alpha \lambda_{1}\left(N_{1}+b_{r, 1}-b_{1}^{s}\right)+(1-\alpha) \lambda_{2}\left(N_{2}+b_{r, 2}-b_{2}^{s}\right) ; \varepsilon_{P_{I F}}=$ $\alpha \varepsilon_{P_{1}}+(1-\alpha) \varepsilon_{P_{2}}$ and $\varepsilon_{L_{I F}}=\alpha \varepsilon_{L_{1}}+(1-\alpha) \varepsilon_{L_{2}}$. It is well known that the tropospheric delay is composed of dry and wet components. The Saastamoinen model can be used to correct for the dry tropospheric delay, while the wet tropospheric delay is expressed as the product of a mapping function $M_{W}$ and a zenith wet delay $z w d$, and the zenith wet delay must be estimated due to its volatility. By applying PPP-B2b orbits and clock offsets, Equation (9) can be linearized as:

$$
\left\{\begin{array}{c}
p_{I F}=-\boldsymbol{e} \cdot \boldsymbol{x}+c \cdot \delta t_{r}+M_{W} \cdot z w d+\varepsilon_{P_{I F}} \\
l_{I F}=-\boldsymbol{e} \cdot \boldsymbol{x}+\boldsymbol{c} \cdot \delta t_{r}+M_{W} \cdot z w d+\lambda_{I F} \cdot N_{I F}+\varepsilon_{L_{I F}}
\end{array}\right.
$$

where $e$ denotes the unit vector in the receiver-to-satellite direction, and $x$ is the receiver position increment. As we can see from this equation, the unknown parameters only remain the receiver position increment vector $x$, the receiver clock offset $\delta t_{r}$, the zenith wet delay $z w d$ and the ionosphere-free ambiguity $\lambda_{I F} N_{I F}$. By adopting a Kalman filter scheme, the unknown parameters can be exactly estimated.

\section{Experiments, Results and Discussion}

To evaluate the precision of orbit and clock corrections and PPP performance, PPP-B2b messages over a 3-day period were collected from 5 October 2020 to 7 October 2020. The collected PPP-B2b messages were broadcast from C59 and C60. The PPP-B2b message types, as well as the corresponding sample rates and nominal validity time, over the selected 3-day period are listed in Table 2. There is only one message broadcast per second. Hence the total number of PPP-b2b messages is expected to be 86,400 in one day for each GEO satellite. We counted the number of received messages for each message type. The percentage of different message types is presented in Figure 1. There were just 3 epochs of PPP-B2b messages missing, and only PPP-B2b corrections of GPS and BDS-3 satellites were broadcast during the selected period.

Table 2. The PPP-B2b message information.

\begin{tabular}{ccc}
\hline Message Type & Sample Rate (s) & Nominal Validity (s) \\
\hline 1 & 48 & - \\
2 & 48 & 96 \\
3 & 48 & 86,400 \\
4 & 6 & 12 \\
63 & - & - \\
\hline
\end{tabular}






Figure 1. The percentages of different PPP-b2b message types (5 October 2020 to 7 October 2020).

Two sets of experiments were carried out to assess the BDS PPP-B2b service. Firstly, the precision of PPP-B2b orbit and clock corrections was evaluated by using precise products from GFZ (GBM) as references. Secondly, the PPP tests, including static mode and kinematic mode, were conducted to assess positioning performance.

\subsection{Assessment Results of PPP-B2b Orbit/Clock Corrections}

The availability of BDS-3/GPS satellites' PPP-B2b orbit and clock offset corrections are depicted in Figure 2. BDS PPP-B2b service contains 29 GPS satellites and 27 BDS-3 satellites during the period from 5 October 2020 to 7 October 2020.

GBM precise orbit/clock products were downloaded from ftp:/ / ftp.gfz-potsdam.de/ GNSS/products/mgex/on 15 December 2020 and used as references. Up to October 2020, GBM precise products include BDS-3 satellites of C19-C30, C32-C46, C60. The orbit and clock accuracy for BDS-3 MEOs could reach centimeter-level, and that for BDS-3 GEOs and IGSOs is at decimeter-level [43]. Given that the accuracy of GBM orbits/clocks for BDS-3 GEOs and IGSOs is at decimeter-level, we excluded BDS-3 GEOs and IGSOs from the assessment. For GPS satellites, the GBM products exhibit an orbit/clock accuracy at $2-3 \mathrm{~cm}[44]$. 


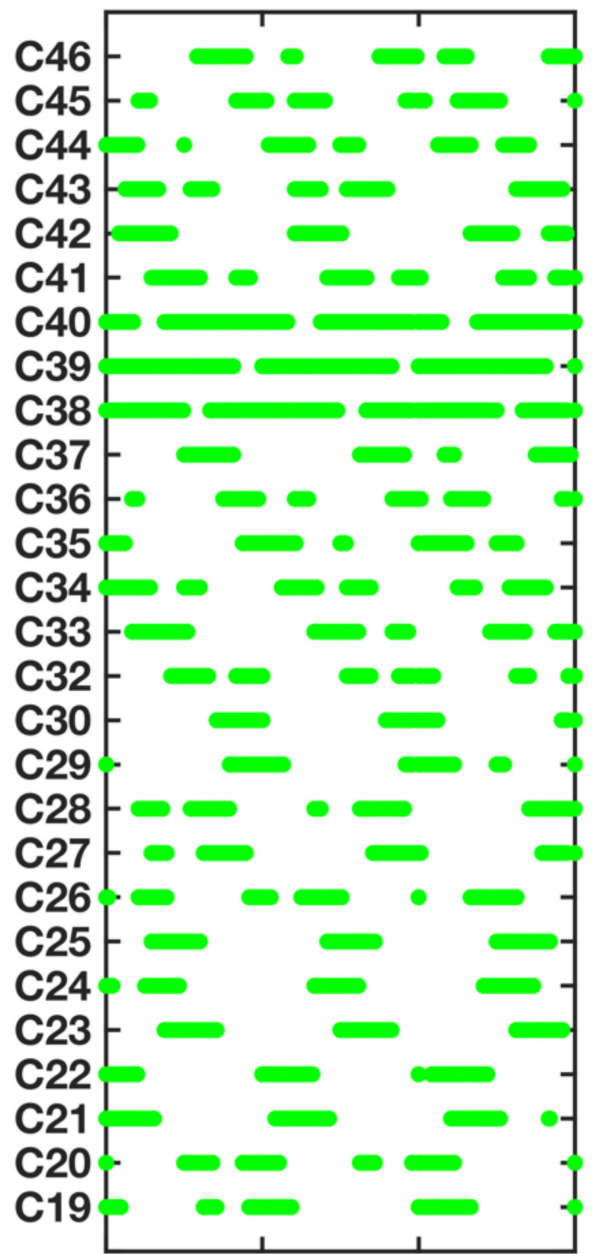

5 Oct. 6 Oct. 7 Oct. Year(2020)

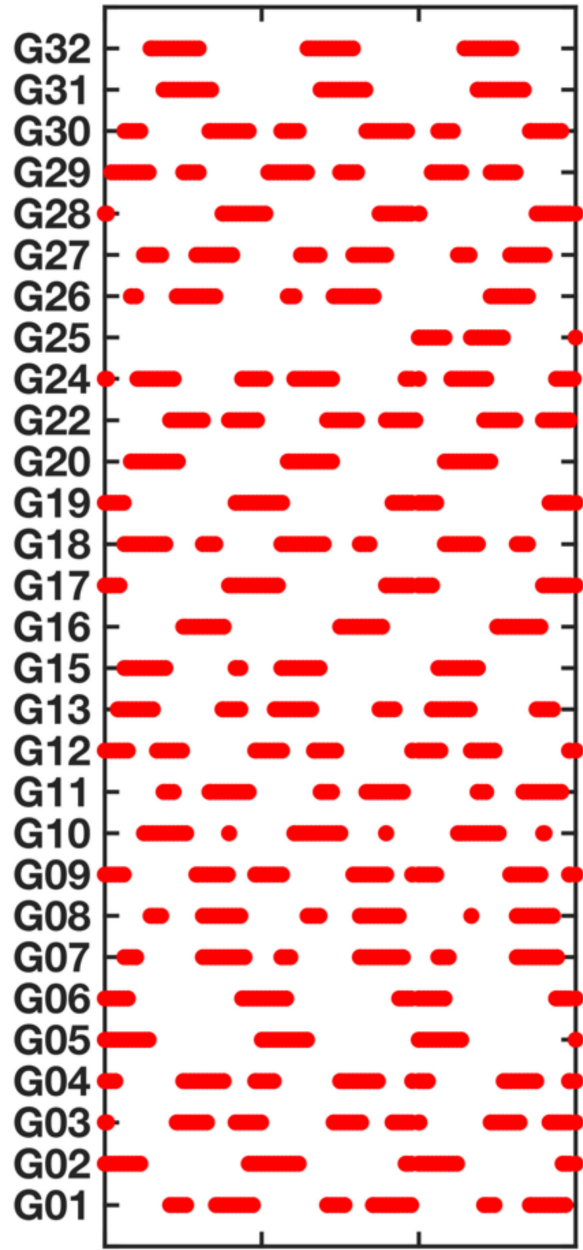

5 Oct. 6 Oct. 7 Oct.

Year(2020)

Figure 2. The availability of PPP-B2b orbit/clock corrections for BDS-3/GPS satellites from 5 October 2020 to 7 October 2020.

Firstly, we recovered the PPP-B2b precise orbits and clock offsets at a 30-s sampling rate by using PPP-B2b messages and broadcast ephemeris data. At the same time, the GBM precise ephemeris were interpolated to the same sample according to the algorithm described in [45]. The satellite PCOs were corrected according to Equation (4). Considering that there was only a three-day data arc, the Helmert transformation parameters, obtained from the China satellite navigation office (CSNO) [30], were directly adopted instead of estimated. The clock differences caused by different signals were also corrected according to Equation (6). Subsequently, the orbit/clock errors were calculated as described in Section 2. The orbit errors in the direction of along-track, cross-track and radial, as well as the clock offset errors, are shown in Figures 3 and 4. Most of the PPP-B2b orbit errors are within the range of $\pm 0.5 \mathrm{~m}$. The GPS satellites show larger errors in the along-track component compared to the cross-track/radial components. For BDS-3 satellites, the errors in the cross-track component seem to be larger than for the other two directions. 




- $\mathrm{G} 01$

- G02

- G03

- G04

- G05

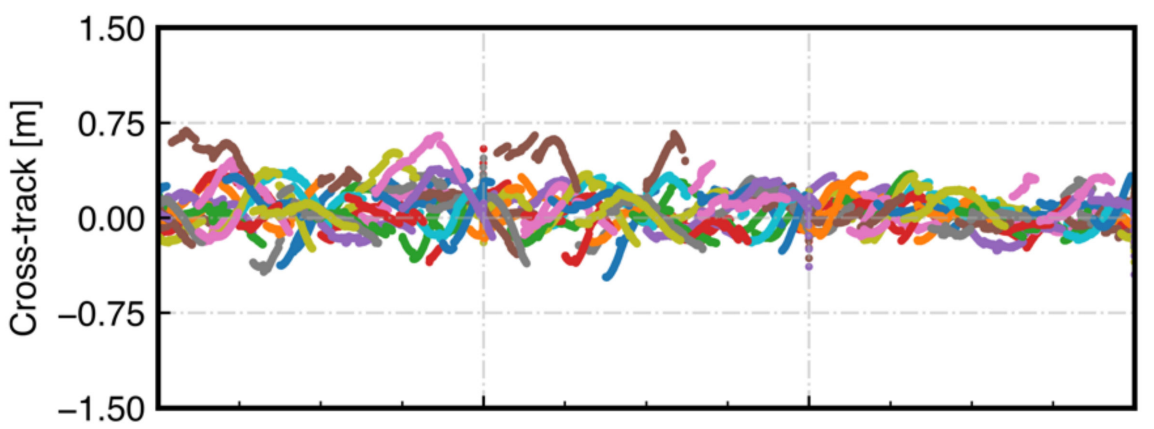

- G06

- G07

- G08

- G09

- $\mathrm{G} 10$

- G11

- G12

- $\mathrm{G} 13$

- G15



- G16

- $\mathrm{G} 17$

- $\mathrm{G} 18$

- G19

- G20

- G22

- G24

- G25

- G26

- G27



- G28

- G29

- G30

- G31 G32

Figure 3. GPS PPP-B2b orbit and clock errors from 5 October 2020 to 7 October 2020. 


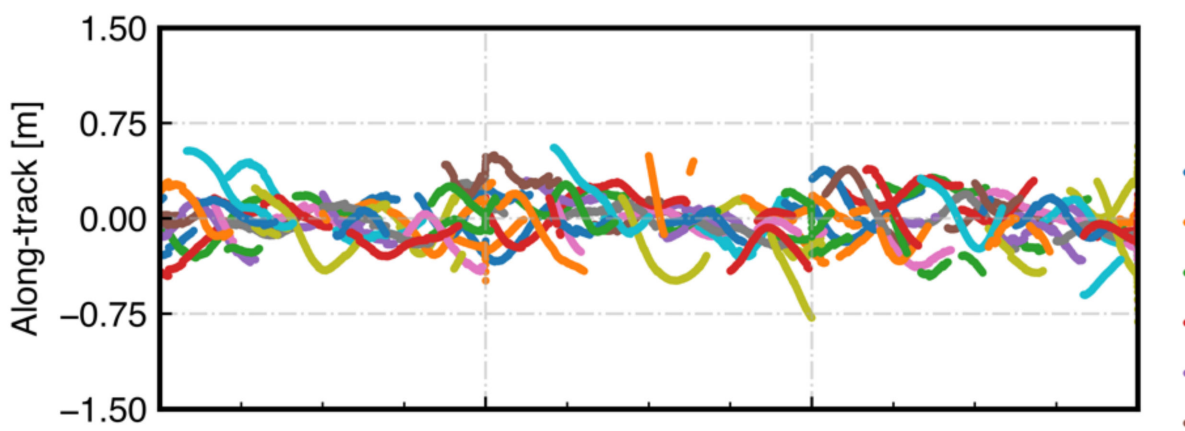

C19

- C20

- C21

- C22

- $\mathrm{C} 23$

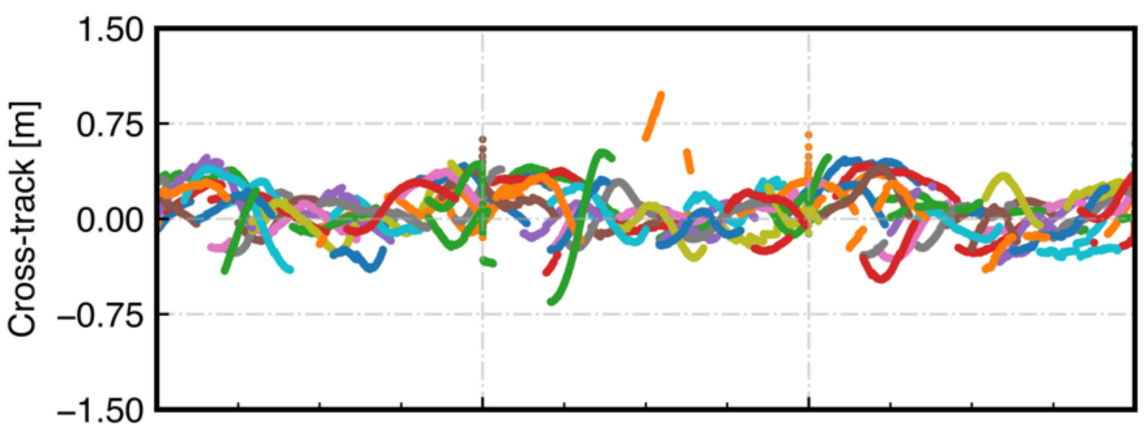

C24

- C25

C26

- C27

C28

- $\mathrm{C} 29$

- C30

- C32

- C33

- C34

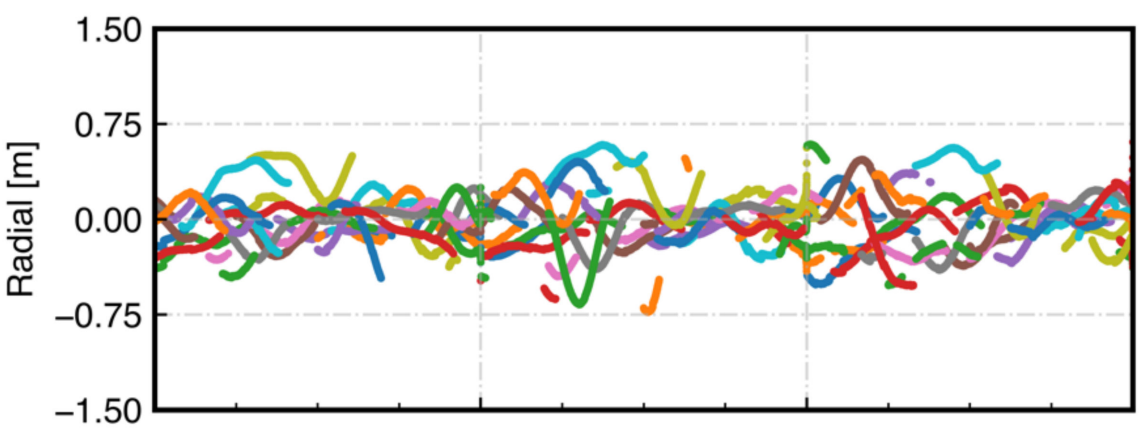

- C35

- C36

- $\mathrm{C} 37$

C41

C42

- $\mathrm{C} 43$

- C44

- C45



Figure 4. BDS PPP-B2b orbit and clock errors from 5 October 2020 to 7 October 2020.

The root mean square (RMS) of PPP-B2b orbit errors was counted to assess the precision of PPP-B2b precise orbit corrections. Considering that a common constant of clock offset errors can be absorbed into the receiver clock offset parameter, the standard deviation (STD) of PPP-B2b precise clock offset errors was adopted to evaluate the precision of PPP-B2b clock offset corrections. Figures 5 and 6 show the RMS values of PPP-B2b orbit errors, and the STD value of PPP-B2b clock offset errors over a period of 3 days. Table 3 further presents the average RMS values of orbit errors in the along-track/cross-track/radial components, and the average STD values of clock offset errors. In general, the accuracy 
of the PPP-B2b orbits can reach decimeter level for GPS satellites and BDS-3 MEOs. The accuracy of the PPP-B2b clock offsets is better than $3.0 \mathrm{~cm}$.

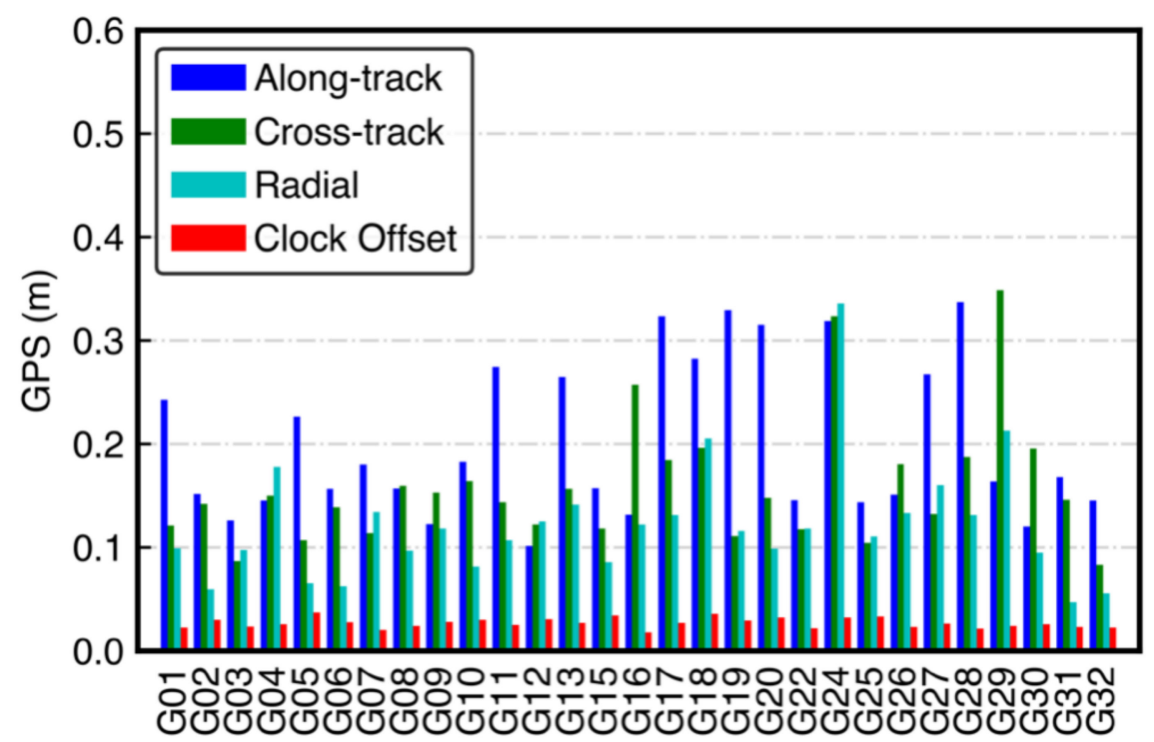

Figure 5. RMS values of GPS PPP-B2b orbit errors and STD values of clock errors.

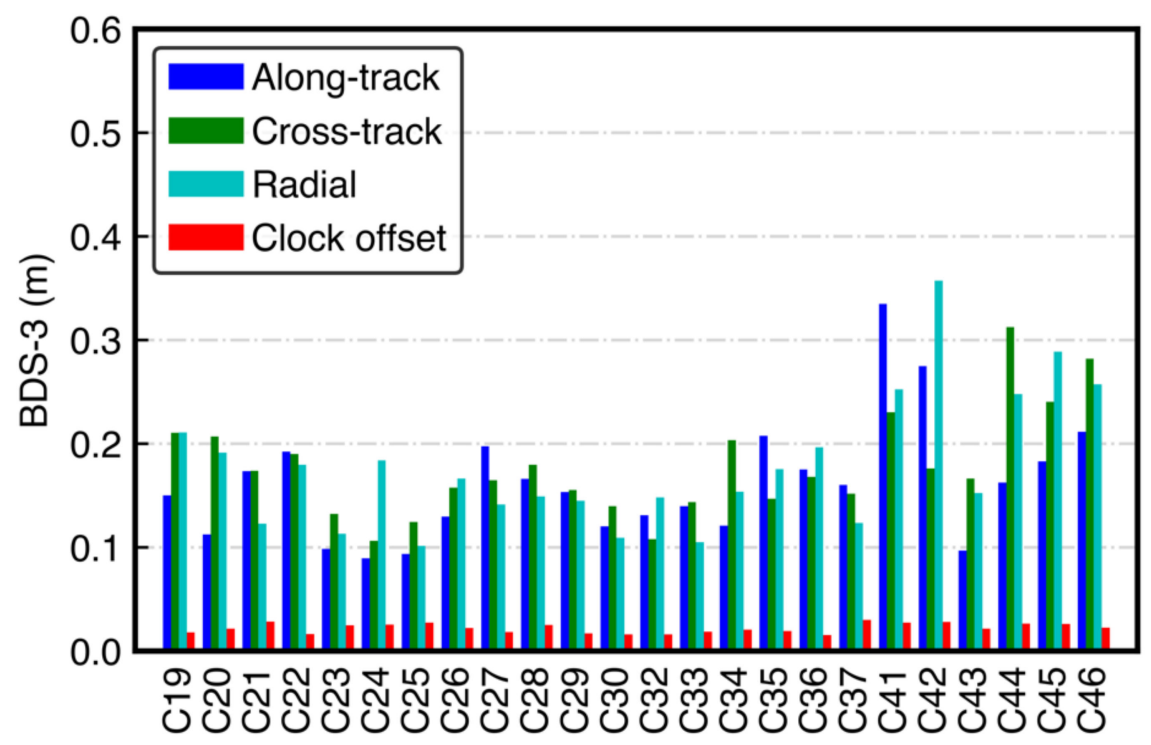

Figure 6. RMS values of BDS PPP-B2b orbit errors and STD values of clock errors.

Table 3. The average STD and RMS of BDS-3/GPS PPP-B2b orbits and clock errors (unit: $\mathrm{cm}$ ).

\begin{tabular}{ccccc}
\hline & RMS-A $^{\mathbf{1}}$ & RMS-C $^{\mathbf{2}}$ & RMS-R $^{\mathbf{3}}$ & STD-CLK $^{\mathbf{4}}$ \\
\hline GPS & 16.0 & 13.4 & 10.4 & 2.7 \\
BDS & 13.1 & 14.5 & 13.8 & 2.2
\end{tabular}

${ }^{1}$ RMS-A denotes the average RMS value of orbit errors in the direction of along-track. ${ }^{2}$ RMS-C denotes the average RMS value of orbit errors in the direction of cross-track. ${ }^{3}$ RMS-R denotes the average RMS value of orbit errors in the direction of radial. ${ }^{4}$ STD-CLK stands for the average STD value of clock offset errors.

\subsection{PPP Tests}

To investigate the positioning performance with the PPP-B2b service, PPP tests in static and kinematic mode were carried out. For comparison, the static and kinematic 
PPP solutions were also obtained by using GBM products. We collected BDS-3/GPS observations from 4 iGMAS stations. The geographical distribution of the 4 selected iGMAS stations, located between $20^{\circ} \mathrm{N}-40^{\circ} \mathrm{N}$ and $100^{\circ} \mathrm{E}-130^{\circ} \mathrm{E}$, is shown in Figure 7 . The daily observation files were split into 4 -h sessions, and the PPP processing was restarted every $4 \mathrm{~h}$. Once the data outage was larger than $1 \mathrm{~min}$, the corresponding 4 -h session would not be processed. Table 4 summarized our PPP processing strategies. Notice that kinematic PPP was simulated by estimating positions independently epoch-by-epoch, which is similar to the estimation of the position in the kinematic PPP mode. The coordinates obtained from the iGMAS weekly SINEX solution file were used as references [46].

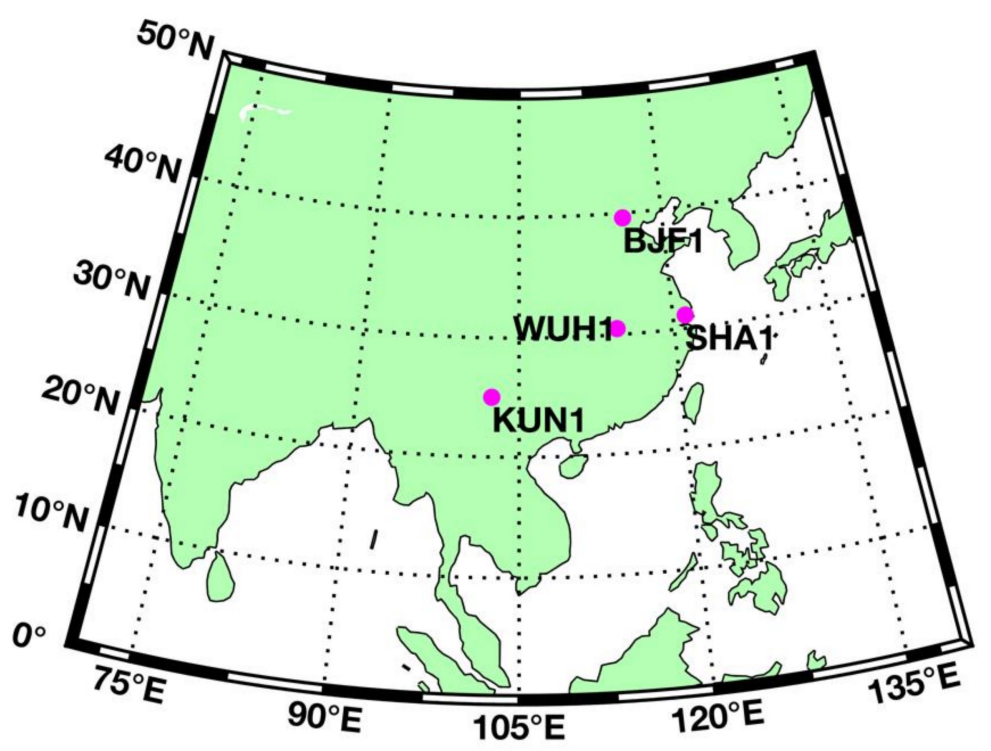

Figure 7. Location of 4 selected iGMAS stations.

Table 4. Strategies of PPP processing.

\begin{tabular}{cc}
\hline Item & Models/Strategies \\
\hline GNSS System & GPS and BDS-3 \\
Signal selection & GPS: L1/L2 and BDS-3: B1C/B2a \\
Observables & Dual-frequency code/phase ionosphere-free combinations \\
Sampling rate & $30 \mathrm{~s}$ \\
Cutoff elevation & $10^{\circ}$ \\
Observable noise & Raw code: 0.5 m in zenith direction \\
Weight method & Raw phase: 0.005 m in zenith direction \\
Phase windup & Elevation dependent weight [38] \\
Relativistic effect & Corrected [41] \\
Sagnac effect & Corrected [40] \\
Shapiro time delay & Corrected [40] \\
Tidal effect & Corrected [40] \\
& Solid tide, ocean loading and pole tide were corrected according \\
to IERS Conventions 2010 [42] & Zenith dry delay: corrected with Saastamoinen model, while \\
& meteorological parameters were calculated by applying global \\
pressure and temperature (GPT) model [47]
\end{tabular}




\subsubsection{Static Mode}

The RMS values of positioning errors of the final $10 \mathrm{~min}$ were counted to assess the positioning accuracy in the static mode. Figures 8-11 show the PPP positioning accuracy at the stations of BJF1, KUN1, SHA1, and WUH1. Among these figures, several sessions positioning accuracy are not provided because of the GNSS data outage. In general, the static PPP performance with the PPP-B2b service is slightly worse than that with GBM products. The positioning accuracy with the PPP-B2b service in the north component is better than those in the east/up components. The positioning accuracy with the PPP-B2b service in the north component is better than $3.5 \mathrm{~cm}$, while a positioning accuracy of better than $4.5 \mathrm{~cm}$ can be achieved in the north/up components. The positioning accuracy with the PPP-B2b service of all sessions is at the centimeter level. The positioning accuracy with GBM products is better than $3.5 \mathrm{~cm}$ in the east/north/up components. For all four stations, the average positioning accuracy with PPP-B2b service varies by $2.5-3.1 \mathrm{~cm}$ in the horizontal component, and $1.9-2.5 \mathrm{~cm}$ in the vertical component. While the average positioning accuracy with GBM products varies by $1.5-1.8 \mathrm{~cm}$ in the horizontal, and 1.1-1.6 $\mathrm{cm}$ in the vertical direction. The detailed statistics are presented in Table 5.

Table 5. The average positioning accuracy at the four stations (unit: $\mathrm{cm}$ ).

\begin{tabular}{lcccccccccc}
\hline & \multicolumn{4}{c}{ PPP-B2b Service } & \multicolumn{5}{c}{ GBM Products } \\
\cline { 2 - 11 } & $\mathbf{E}^{\mathbf{1}}$ & $\mathbf{N}^{\mathbf{2}}$ & $\mathbf{U}^{\mathbf{3}}$ & $\mathbf{H}^{\mathbf{4}}$ & 3D $^{\mathbf{5}}$ & $\mathbf{E}^{\mathbf{1}}$ & $\mathbf{N}^{\mathbf{2}}$ & $\mathbf{U}^{\mathbf{3}}$ & $\mathbf{H}^{\mathbf{4}}$ & 3D $^{\mathbf{5}}$ \\
\hline BJF1 & 2.2 & 1.8 & 2.4 & 2.8 & 3.7 & 1.1 & 1.4 & 1.3 & 1.8 & 2.2 \\
KUN1 & 2.1 & 1.3 & 2.2 & 2.5 & 3.3 & 1.1 & 1.0 & 1.1 & 1.5 & 1.9 \\
SHA1 & 2.7 & 1.4 & 2.5 & 3.0 & 3.9 & 1.2 & 1.1 & 1.6 & 1.6 & 2.3 \\
WUH1 & 2.4 & 1.8 & 1.9 & 3.0 & 3.6 & 1.0 & 1.4 & 1.5 & 1.7 & 2.3 \\
\hline
\end{tabular}

${ }^{1} \mathrm{E} /{ }^{2} \mathrm{~N} /{ }^{3} \mathrm{U}$ Stands for the directions of east, north and up; ${ }^{4} \mathrm{H} /{ }^{5}$ 3D denote horizontal and 3-dimensional.
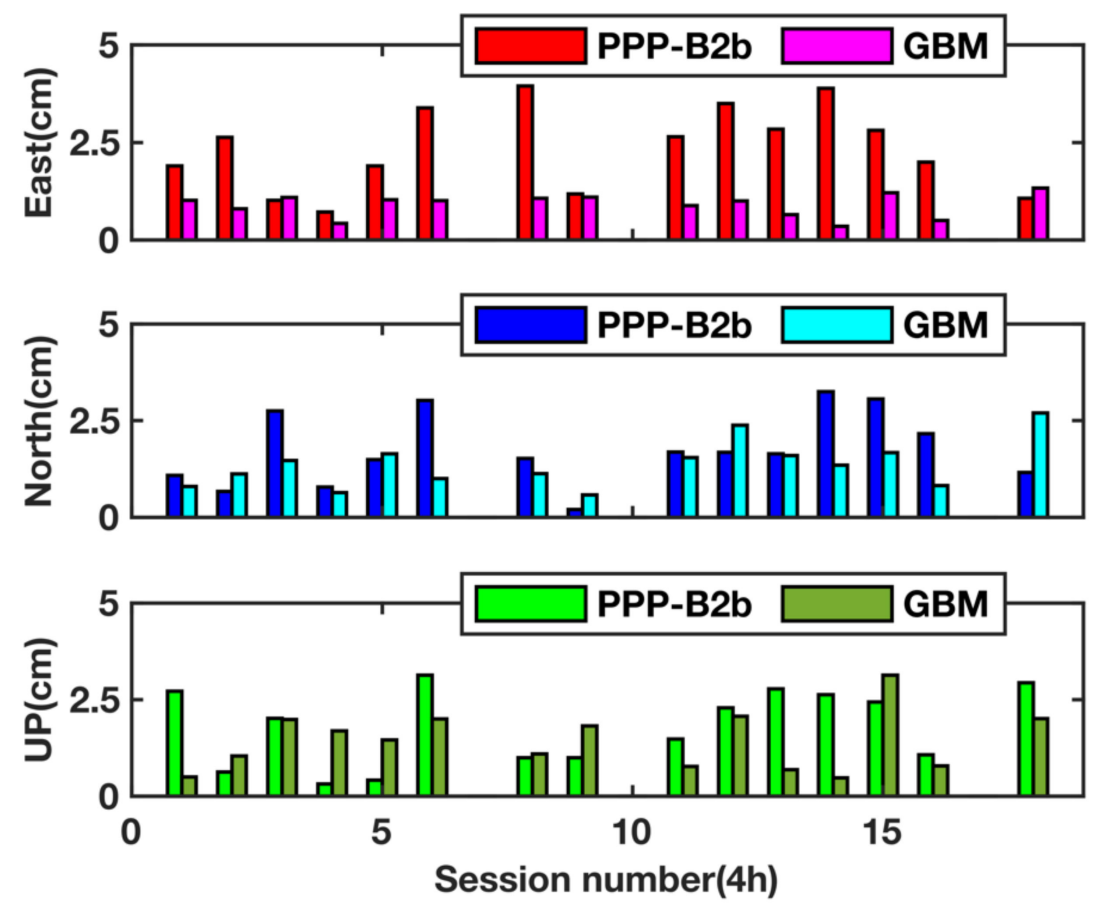

Figure 8. Positioning accuracy of static PPP with different data sessions at WUH1 station. 

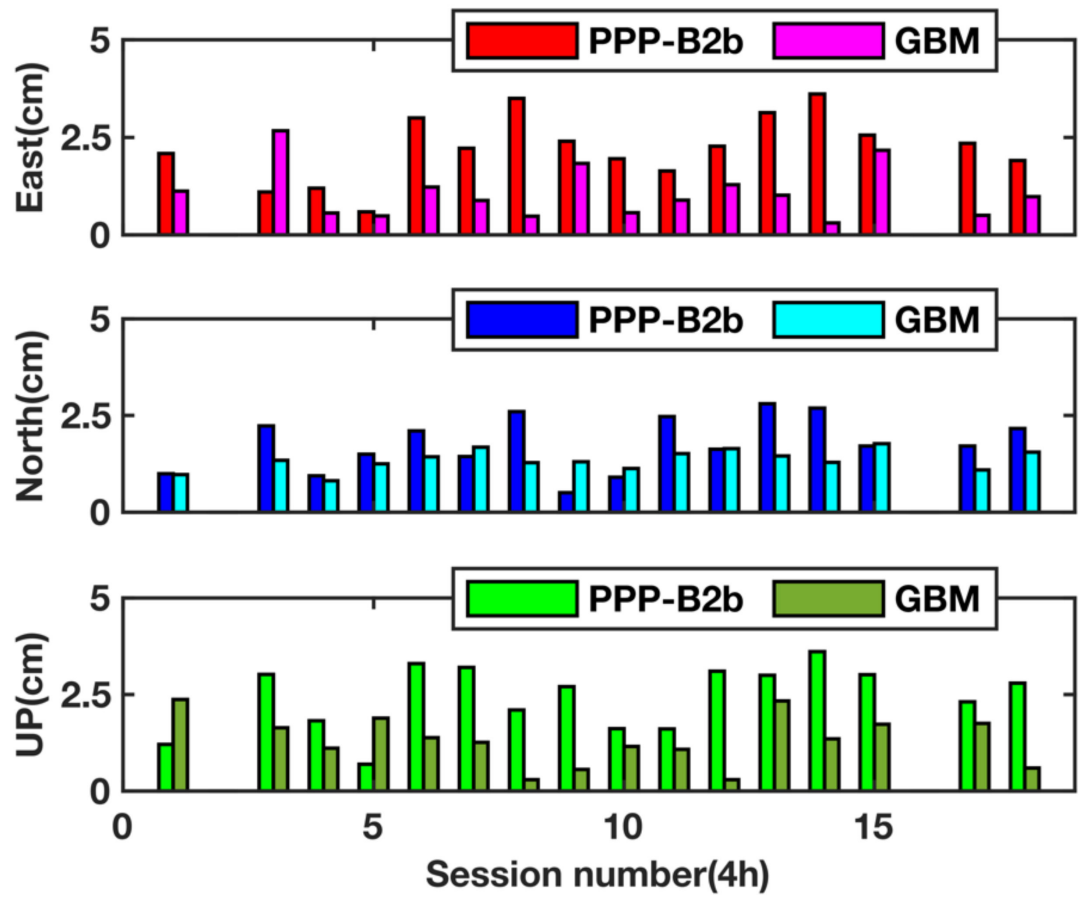

Figure 9. Positioning accuracy of static PPP with different data sessions at BJF1 station.
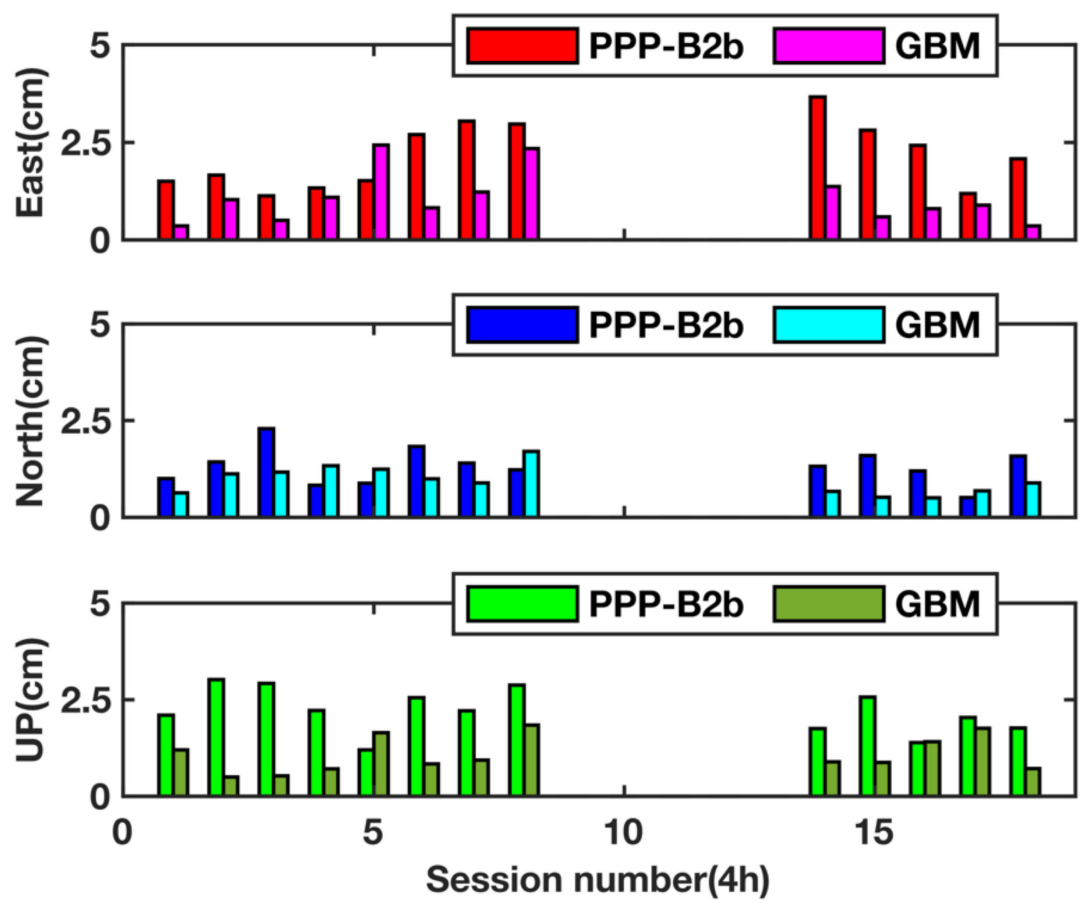

Figure 10. Positioning accuracy of static PPP with different data sessions at KUN1 station. 

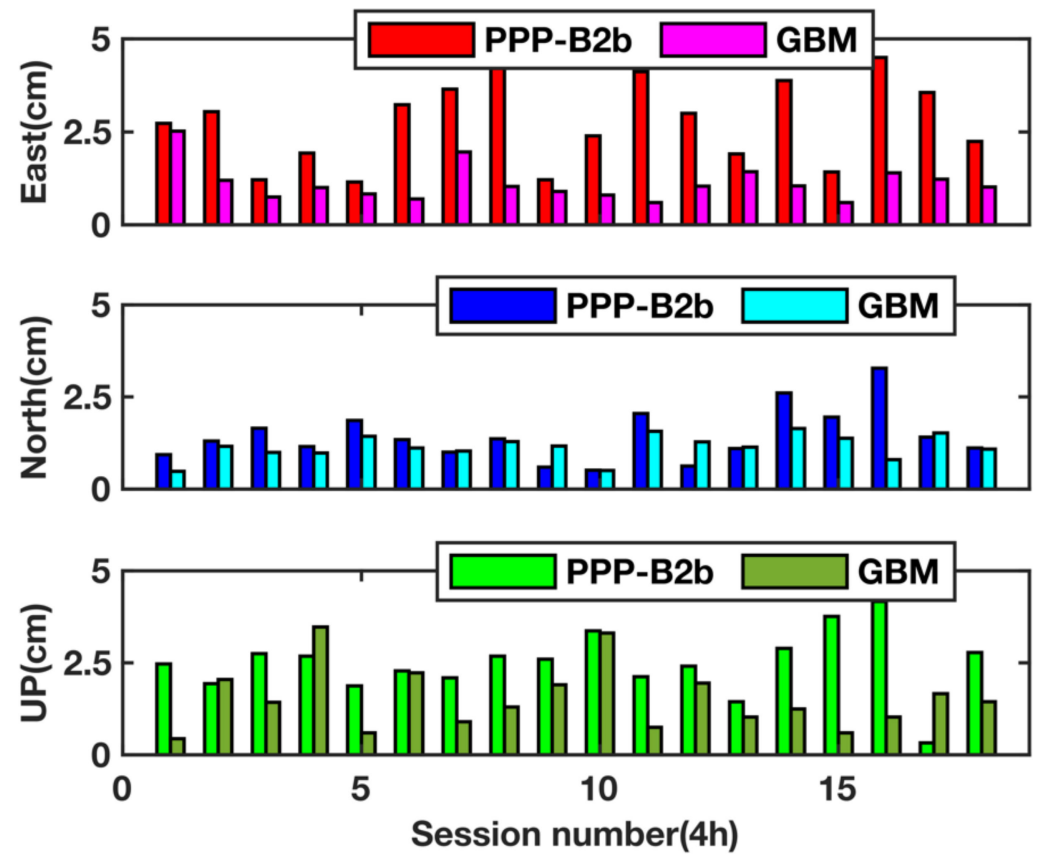

Figure 11. Positioning accuracy of static PPP with different data sessions at SHA1 station.

Convergence time (CT) is also a crucial factor to assess the static PPP performance. As described in the official document [7], the positioning performance with PPP-B2b service is better than $30 \mathrm{~cm}$ in the horizontal component and better than $60 \mathrm{~cm}$ in the vertical component with a confidence level of $95 \%$. Hence, the convergence time was defined to achieve the horizontal positioning accuracy better than $30 \mathrm{~cm}$, the vertical positioning accuracy better than $60 \mathrm{~cm}$, and keep such a positioning accuracy at least $5 \mathrm{~min}$ in this paper. The convergence time of static PPP at each iGMAS station is shown in Figure 12. As visible, the convergence time with PPP-B2b service is $18.0 / 17.0 / 18.8 / 16.9 \mathrm{~min}$ at 4 iGMAS stations. When GBM products are used, the convergence time is 8.2/11.8/10.6/9.8 min, respectively.


Figure 12. Convergence time of static PPP at different data sessions. 


\subsubsection{Kinematic Mode}

The kinematic PPP positioning errors at the stations of BJF1, KUN1, SHA1 and WUH1 are presented in Figures 13-16, respectively. Similarly, there is also a lack of some sessions positioning results, due to GNSS data outage. One can see that the positioning accuracy with the PPP-B2b service in the east/north/up components is all within one decimeter after convergence.

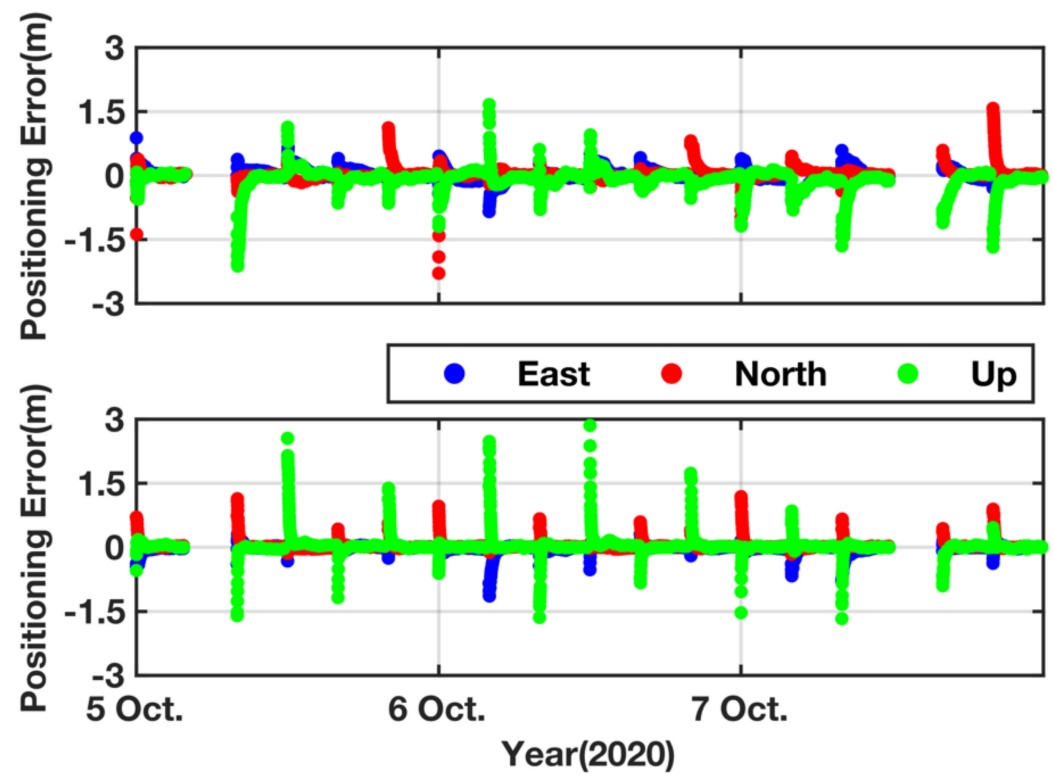

Figure 13. Kinematic PPP positioning errors at the BJF1 station (top panel for PPP-B2b and bottom panel for GBM).

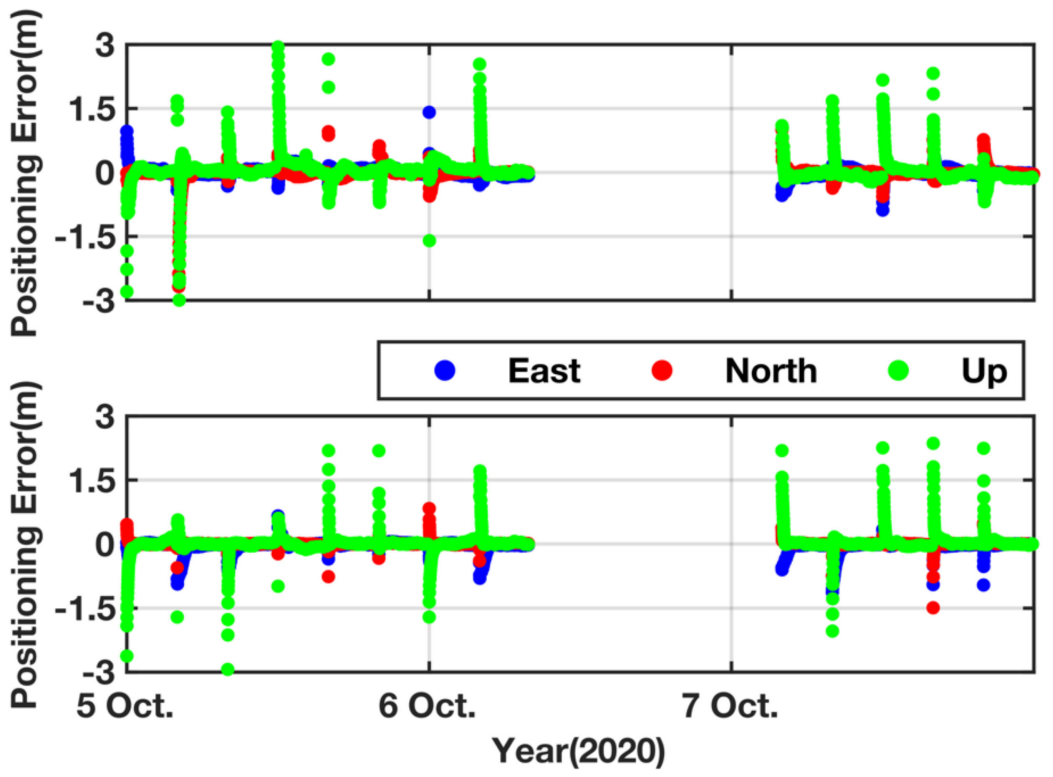

Figure 14. Kinematic PPP positioning errors at the KUN1 station (top panel for PPP-B2b and bottom panel for GBM). 


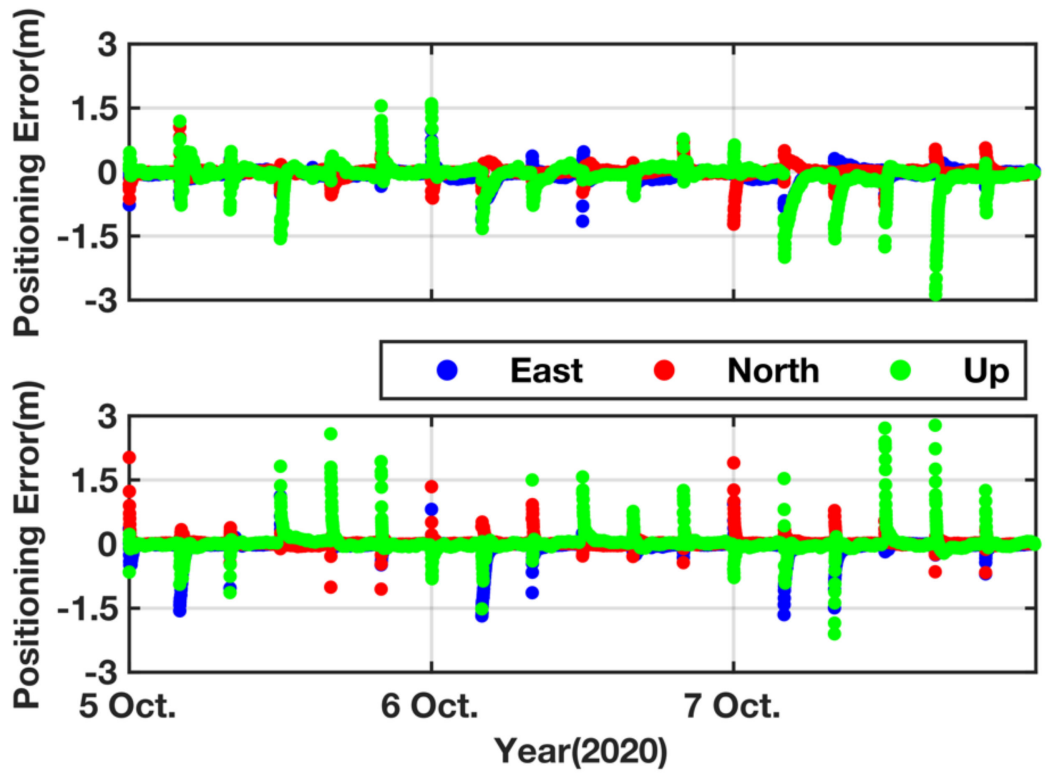

Figure 15. Kinematic PPP positioning errors at the SHA1 station (top panel for PPP-B2b and bottom panel for GBM).

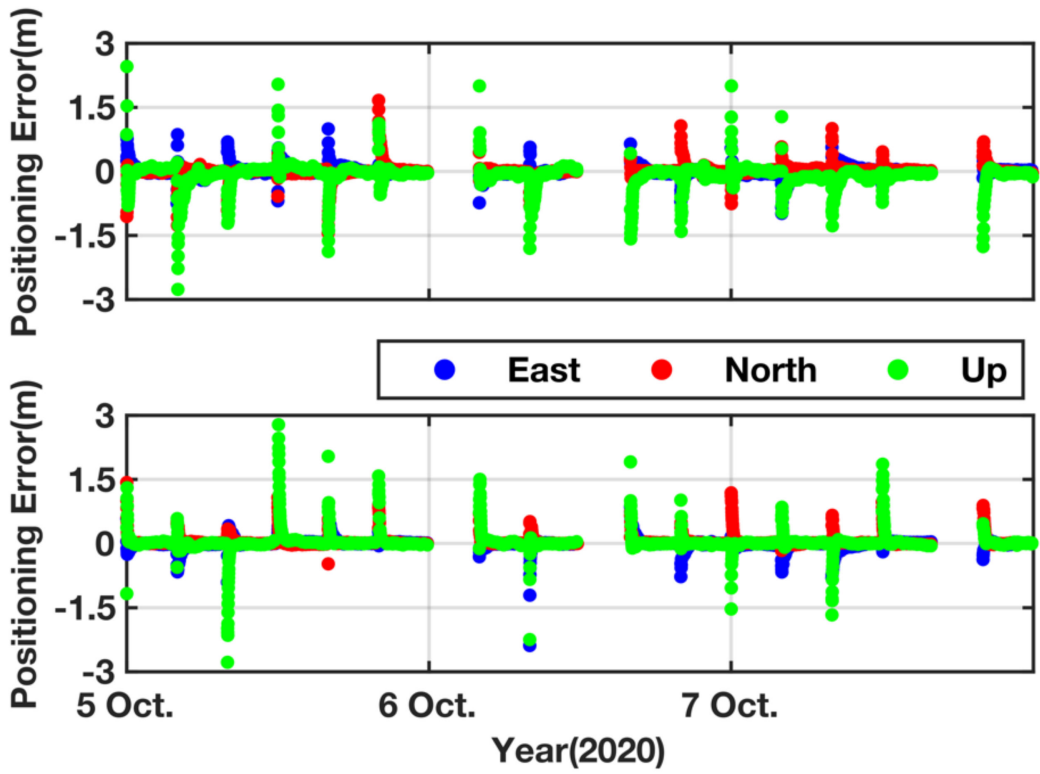

Figure 16. Kinematic PPP positioning errors at the WUH1 station (top panel for PPP-B2b and bottom panel for GBM).

The RMS values of positioning errors were counted for 4 iGMAS stations, and the results are presented in Table 6 . It should be noted that the positioning errors of the first $30 \mathrm{~min}$ at each session have been removed, in order to exclude the positioning results before full convergence. For both types of products, the positioning accuracy in the north component is apparently better than those in the other two components. In term of PPP performance with the PPP-B2b service, the horizontal positioning accuracy ranges from 8.0 to $9.6 \mathrm{~cm}$, with an average value of $8.9 \mathrm{~cm}$, and the 3-dimensional positioning accuracy is all within $13 \mathrm{~cm}$, with an average value of $11.8 \mathrm{~cm}$. When using the GBM products, the average horizontal positioning accuracy can reach $4.2 \mathrm{~cm}$, and the average 3-dimensional positioning accuracy is $5.7 \mathrm{~cm}$. 
Table 6. The positioning accuracy of kinematic PPP at all four stations (unit: $\mathrm{cm}$ ).

\begin{tabular}{|c|c|c|c|c|c|c|c|c|c|c|}
\hline & \multicolumn{5}{|c|}{ PPP-B2b Service } & \multicolumn{5}{|c|}{ GBM Products } \\
\hline & E & $\mathbf{N}$ & $\mathbf{U}$ & $\mathbf{H}$ & $3 \mathrm{D}$ & E & $\mathbf{N}$ & $\mathbf{U}$ & $\mathbf{H}$ & $3 \mathrm{D}$ \\
\hline BJF1 & 8.0 & 3.8 & 8.6 & 8.8 & 12.3 & 3.3 & 2.5 & 3.5 & 4.1 & 5.4 \\
\hline KUN1 & 9.2 & 3.1 & 8.3 & 9.6 & 12.7 & 3.9 & 1.5 & 4.3 & 4.2 & 6.0 \\
\hline SHA1 & 7.1 & 3.6 & 7.5 & 8.0 & 10.9 & 3.5 & 2.4 & 4.5 & 4.2 & 6.2 \\
\hline WUH1 & 8.1 & 4.0 & 7.5 & 9.0 & 11.3 & 3.4 & 2.2 & 3.0 & 4.1 & 5.0 \\
\hline
\end{tabular}

\section{Conclusions}

At present, the PPP-B2b service is available for users in and around China. In this study, an initial assessment of the BDS PPP-B2b service was carried out based on the collected 3-day data. Firstly, the availability of PPP-B2b messages was analyzed. The PPP$\mathrm{B} 2 \mathrm{~b}$ service only provided the satellite orbit correction, clock correction, and differential code bias of BDS-3/GPS. The availability of PPP-B2b messages was near to $100 \%$; the missing number of PPP-B2b messages was only 3 epochs during the 3 -day period. With GBM precise ephemeris products as references, the precision of PPP-B2b orbit and clock corrections were evaluated. The accuracy of PPP-B2b orbits in the direction of radial along-track and cross-track were $0.104 / 0.169 / 0.134 \mathrm{~m}$ for GPS. The corresponding accuracy obtained for BDS-3 MEOs was 0.138/0.131/0.145 m. Generally, the standard deviation of B2b clock offsets was better than $3.0 \mathrm{~cm}$.

PPP tests, both in static and kinematic mode, were also conducted to further evaluate the positioning performance of the PPP-B2b service. Regarding static PPP, the convergence time was about $17.7 \mathrm{~min}$, and the average positioning accuracy in the direction of east, north and up were $2.4 / 1.6 / 2.3 \mathrm{~cm}$, respectively. As for simulated kinematic PPP, the average positioning accuracies were $8.1 / 3.6 / 8.0 \mathrm{~cm}$ in the east/north/up components, respectively. The results of PPP tests demonstrated that the positioning accuracy could reach centimeter-level for static applications, and decimeter-level positioning accuracy could be achieved for kinematic applications.

Author Contributions: Conceptualization, Z.N. and Z.W.; methodology, Z.N. and X.X.; software, Z.N. and X.X.; validation, X.X. and J.D.; formal analysis, X.X. and J.D.; writing-original draft preparation, X.X.; writing-review and editing, Z.N.; visualization, X.X. and J.D.; supervision, Z.W.; project administration, Z.W.; funding acquisition, Z.N and Z.W. All authors have read and agreed to the published version of the manuscript.

Funding: This study was funded by the National Key Research and Development Program of China (Nos. 2019YFC1509205, 2019YFC1509204), China Postdoctoral Science Foundation (No. 2020M672168), the Fundamental Research Funds for the Central Universities (No. 20CX06044A) and Qingdao Postdoctoral Application Research Project (No. QDYY20190077).

Institutional Review Board Statement: Not applicable.

Informed Consent Statement: Not applicable.

Data Availability Statement: The datasets analyzed in this study are managed by the College of Oceanography and Space Informatics, China University of Petroleum, Qingdao, China and can be available on request from the corresponding author.

Acknowledgments: We greatly appreciate iGMAS and GFZ for providing multi-GNSS observation data and products.

Conflicts of Interest: The authors declare no conflict of interest.

\section{References}

1. Yang, Y.; Li, J.; Xu, J.; Tang, J.; Guo, H.; He, H. Contribution of the Compass satellite navigation system to global PNT users. Chin. Sci. Bull. 2011, 56, 2813-2819. [CrossRef]

2. China Satellite Navigation Office. Development of the BeiDou Navigation Satellite System (Version 4.0). Available online: http:/ / www.beidou.gov.cn/xt/gfxz/201912/P020191227430565455478.pdf (accessed on 30 September 2020). 
3. China Satellite Navigation Office. China's BeiDou Navigation Satellite System. Available online: http://www.beidou.gov.cn/xt/ gfxz/201712/P020171221333863515306.pdf (accessed on 30 September 2020).

4. Yang, Y.; Li, J.; Wang, A.; Xu, J.; He, H.; Guo, H.; Shen, J.; Dai, X. Preliminary assessment of the navigation and positioning performance of BeiDou regional navigation satellite system. Sci. China Earth Sci. 2014, 57, 144-152. [CrossRef]

5. Li, X.; Li, X.; Liu, G.; Yuan, Y.; Freeshah, M.; Zhang, K.; Zhou, F. BDS multi-frequency PPP ambiguity resolution with new B2a/B2b/B2a + b signals and legacy B1I/B3I signals. J. Geod. 2020, 94, 1-15. [CrossRef]

6. Yang, Y.; Mao, Y.; Sun, B. Basic performance and future developments of BeiDou global navigation satellite system. Satell. Navig. 2020, 1, 1-8. [CrossRef]

7. China Satellite Navigation Office. The Application Service Architecture of BeiDou Navigation Satellite System (Version 1.0) Available online: http:/ / www.beidou.gov.cn/xt/gfxz/201912/P020191227333024390305.pdf (accessed on 30 September 2020).

8. Zumberge, J.F.; Heflin, M.B.; Jefferson, D.C.; Watkins, M.M.; Webb, F.H. Precise point positioning for the efficient and robust analysis of GPS data from large networks. J. Geophys. Res. Solid Earth 1997, 102, 5005-5017. [CrossRef]

9. Kouba, J.; Héroux, P. Precise Point Positioning Using IGS Orbit and Clock Products. GPS Solut. 2001, 5, 12-28. [CrossRef]

10. Zhang, B.; Chen, Y.; Yuan, Y. PPP-RTK based on undifferenced and uncombined observations: Theoretical and practical aspects. J. Geod. 2019, 93, 1011-1024. [CrossRef]

11. Geng, J.; Teferle, F.N.; Meng, X.; Dodson, A.H. Kinematic precise point positioning at remote marine platforms. GPS Solut. 2010, 14, 343-350. [CrossRef]

12. Alkan, R.M.; Saka, M.H.; Ozulu, M.; İlçi, V. Kinematic precise point positioning using GPS and GLONASS measurements in marine environments. Measurement 2017, 109, 36-43. [CrossRef]

13. Nie, Z.; Wang, B.; Wang, Z.; He, K. An offshore real-time precise point positioning technique based on a single set of BeiDou short-message communication devices. J. Geod. 2020, 94, 1-11. [CrossRef]

14. Rocken, C.; Johnson, J.; Van Hove, T.; Iwabuchi, T. Atmospheric water vapor and geoid measurements in the open ocean with GPS. Geophys. Res. Lett. 2005, 32, 1-3. [CrossRef]

15. Xu, P.; Shi, C.; Fang, R.; Liu, J.; Niu, X.; Zhang, Q.; Yanagidani, T. High-rate precise point positioning (PPP) to measure seismic wave motions: An experimental comparison of GPS PPP with inertial measurement units. J. Geod. 2013, 87, 361-372. [CrossRef]

16. Yigit, C.O.; Gurlek, E. Experimental testing of high-rate GNSS precise point positioning (PPP) method for detecting dynamic vertical displacement response of engineering structures. Geomat. Nat. Hazards Risk 2017, 8, 893-904. [CrossRef]

17. Li, X.; Zus, F.; Lu, C.; Ning, T.; Dick, G.; Ge, M.; Wickert, J.; Schuh, H. Retrieving high-resolution tropospheric gradients from multiconstellation GNSS observations. Geophys. Res. Lett. 2015, 42, 4173-4181. [CrossRef]

18. Li, X.; Dick, G.; Ge, M.; Heise, S.; Wickert, J.; Bender, M. Real-time GPS sensing of atmospheric water vapor: Precise point positioning with orbit, clock, and phase delay corrections. Geophys. Res. Lett. 2014, 41, 3615-3621. [CrossRef]

19. Guo, J.; Li, X.; Li, Z.; Hu, L.; Yang, G.; Zhao, C.; Fairbairn, D.; Watson, D.; Ge, M. Multi-GNSS precise point positioning for precision agriculture. Precis. Agric. 2018, 19, 895-911. [CrossRef]

20. Weber, G.; Mervart, L.; Lukes, Z.; Rocken, C.; Dousa, J. Real-time clock and orbit corrections for improved point positioning via NTRIP. In Proceedings of the ION GNSS 2007, Fort Worth, TX, USA, 23-35 September 2007; pp. 1992-1998.

21. El-diasty, M. Development of Real-Time PPP-Based GPS/INS Integration System Using IGS Real-Time Service for Hydrographic Surveys. J. Survey. Eng. 2016, 142, 1-8. [CrossRef]

22. Tegedor, J.; Lapucha, D.; Ørpen, O.; Vigen, E.; Melgard, T.; Strandli, R. The new G4 service: Multi-constellation precise point positioning including GPS, GLONASS, Galileo and BeiDou. In Proceedings of the ION GNSS+ 2015, Tampa, FL, USA, 14-18 September 2015; pp. 1089-1095.

23. Dai, L.; Chen, Y.; Lie, A.; Zeitzew, M.; Zhang, Y. StarFire SF3: Worldwide centimeter-accurate real time GNSS positioning. In Proceedings of the ION GNSS+ 2016, Portland, OR, USA, 12-16 September 2016; pp. 3295-3320.

24. Leandro, R.; Landau, H.; Nitschke, M.; Glocker, M.; Seeger, S.; Chen, X.; Deking, A.; BenTahar, M.; Zhang, F.; Ferguson, K.; et al. RTX positioning: The next generation of $\mathrm{cm}$-accurate real-time GNSS positioning. In Proceedings of the ION GNSS 2011, Portlan, OR, USA, 20-23 September 2011; pp. 1460-1475.

25. Fujita, S.; Sato, Y.; Miya, M.; Ota, K.; Hirokawa, R.; Takiguchi, J. Design of Integrity Function on Centimeter Level Augmentation Service (CLAS) in Japanese Quasi-Zenith Satellite System. In Proceedings of the ION GNSS+ 2016, Portland, OR, USA, 1216 September 2016; pp. 3258-3263.

26. Namie, H.; Okamoto, O.; Kubo, N.; Yasuda, A. Initial performance evaluation of centimeter-class augmentation system using Quasi-Zenith Satellite System. Electron. Commun. Jpn. 2018, 101, 3-10. [CrossRef]

27. Fernandez-Hernandez, I.; Rodríguez, I.; Tobías, G.; Calle, J.D.; Carbonell, E.; Seco-Granados, G.; Simón, J.; Blasi, R. Testing GNSS high accuracy and authentication-galileo's commercial service. Insid. GNSS 2015, 10, 37-48.

28. Susi, M.; Borio, D. Kalman filtering with noncoherent integrations for Galileo E6-B tracking. Navig. J. Inst. Navig. 2020, 67. [CrossRef]

29. Liu, C.; Gao, W.; Liu, T.; Wang, D.; Yao, Z.; Gao, Y.; Nie, X.; Wang, W.; Li, D.; Zhang, W.; et al. Design and implementation of a BDS precise point positioning service. Navig. J. Inst. Navig. 2020, 67, 875-891. [CrossRef]

30. China Satellite Navigation Office. BeiDou Navigation Satellite System Signal in Space Interface Control Document Precise Point Positioning Service Signal PPP-B2b (Beta Version). Available online: http:/ /www.beidou.gov.cn/xt/gfxz/201912/P02019122733 1847498839.pdf (accessed on 30 September 2020). 
31. Chen, Q.; Song, S.; Zhou, W. Accuracy Analysis of GNSS Hourly Ultra-Rapid Orbit and Clock Products from SHAO AC of iGMAS. Remote Sens. 2021, 13, 1022. [CrossRef]

32. Montenbruck, O.; Steigenberger, P.; Hauschild, A. Broadcast versus precise ephemerides: A multi-GNSS perspective. GPS Solut. 2015, 19, 321-333. [CrossRef]

33. Steigenberger, P.; Montenbruck, O. Consistency of MGEX Orbit and Clock Products. Engineering 2020, 6, 898-903. [CrossRef]

34. Zhang, Y.; Kubo, N.; Chen, J.; Chu, F.Y.; Wang, A.; Wang, J. Apparent clock and TGD biases between BDS-2 and BDS-3. GPS Solut. 2020, 24, 1-15. [CrossRef]

35. Lv, Y.; Geng, T.; Zhao, Q.; Xie, X.; Zhou, R. Initial assessment of BDS-3 preliminary system signal-in-space range error. GPS Solut. 2020, 24, 1-13. [CrossRef]

36. Steigenberger, P.; Hugentobler, U.; Loyer, S.; Perosanz, F.; Prange, L.; Dach, R.; Uhlemann, M.; Gendt, G.; Montenbruck, O. Galileo orbit and clock quality of the IGS Multi-GNSS Experiment. Adv. Space Res. 2015, 55, 269-281. [CrossRef]

37. Guo, J.; Xu, X.; Zhao, Q.; Liu, J. Precise orbit determination for quad-constellation satellites at Wuhan University: Strategy, result validation, and comparison. J. Geod. 2016, 90, 143-159. [CrossRef]

38. Leick, A.; Rapoport, L.; Tatarnikov, D. GPS Satellite Surveying, 4th ed.; John Wiley \& Sons: Hoboken, NJ, USA, 2015.

39. Zhang, B.; Hou, P.; Liu, T.; Yuan, Y. A single-receiver geometry-free approach to stochastic modeling of multi-frequency GNSS observables. J. Geod. 2020, 94, 1-21. [CrossRef]

40. Ashby, N. Relativity in the Global Positioning System Imprint/Terms of Use. Living Rev. Relativ. 2003, 6, 1-42. [CrossRef]

41. Wu, J.-T.; Wu, S.C.; Hajj, G.A.; Bertiger, W.I.; Lichten, S.M. Effects of antenna orientation on GPS carrier phase. In Proceedings of the AAS/AIAA Astrodynamics Conference, Durango, CO, USA, 19-22 August 1991; pp. 1647-1660.

42. Petit, G.; Luzum, B. IERS Conventions (2010); Bureau International Des Poids et Mesures Sevres: Frankfurt am Main, Germany, 2010.

43. Sakic, P.; Mansur, G.; Mannel, B. A prototype for a multi-GNSS orbit combination. In Proceedings of the European Navigation Conference, Bonn, Germany, 23-24 November 2020; pp. 1-11.

44. Montenbruck, O.; Steigenberger, P.; Prange, L.; Deng, Z.; Zhao, Q.; Perosanz, F.; Romero, I.; Noll, C.; Stürze, A.; Weber, G.; et al. The Multi-GNSS Experiment (MGEX) of the International GNSS Service (IGS)-Achievements, prospects and challenges. Adv. Space Res. 2017, 59, 1671-1697. [CrossRef]

45. Nie, Z.; Zhou, P.; Liu, F.; Wang, Z.; Gao, Y. Evaluation of orbit, clock and ionospheric corrections from five currently available SBAS L1 services: Methodology and analysis. Remote Sens. 2019, 11, 411. [CrossRef]

46. Cai, H.; Chen, G.; Jiao, W.; Chen, K.; Xu, T.; Wang, H. An Initial Analysis and Assessment on Final Products of iGMAS. In Proceedings of the China Satellite Navigation Conference (CSNC) 2016 Proceeding, Changsha, China, 18-20 May 2016; pp. 515-527.

47. Boehm, J.; Heinkelmann, R.; Schuh, H. Short note: A global model of pressure and temperature for geodetic applications. J. Geod. 2007, 81, 679-683. [CrossRef]

48. Boehm, J.; Niell, A.; Tregoning, P.; Schuh, H. Global Mapping Function (GMF): A new empirical mapping function based on numerical weather model data. Geophys. Res. Lett. 2006, 33, 3-6. [CrossRef] 